\title{
Evaluation of the Feasibility of a Telemedical Examination of the Hip and Pelvis - Early Lessons from the COVID-19 Pandemic
}

\author{
Evaluation der Durchführbarkeit einer telemedizinischen \\ Untersuchung des Hüftgelenks und des Beckens - \\ frühe Lehren aus der COVID-19-Pandemie
}

\section{Authors}

Max Jaenisch*, Hendrik Kohlhof*, Amadeo Touet, Michael Kehrer, Davide Cucchi, Christof Burger, Dieter Christian Wirtz, Kristian Welle**, Koroush Kabir ${ }^{\text {(D)** }}$

\section{Affiliation}

Clinic and Polyclinic for Orthopaedics and Trauma Surgery, Bonn University Clinics, Bonn, Germany

Key words

telemedicine, video consultation, hip, pelvis, COVID-19

\section{Schlüsselwörter}

Telemedizin, Videosprechstunde, Hüfte, Becken, COVID-19

published online $\quad 16.12 .2020$

Bibliography

Z Orthop Unfall 2021; 159: 39-46

DOI 10.1055/a-1289-0779

ISSN 1864-6697

(c) 2020. Thieme. All rights reserved.

Georg Thieme Verlag KG, Rüdigerstraße 14,

70469 Stuttgart, Germany

Supplementary material is available under

https://doi.org/10.1055/a-1289-0779

Correspondence

PD Dr. med. Koroush Kabir

Clinic and Polyclinic for Orthopaedics and Trauma Surgery,

Bonn University Clinics

Venusberg-Campus 1, 53105 Bonn, Germany

Phone: 0228/28715477, Fax: 0228/28715044

koroushkabir@yahoo.com

\section{ABSTRACT}

Introduction Due to the current COVID-19 pandemic, the German Health Ministry has issued restrictions applying to the field of orthopaedics and trauma surgery. Besides postponement of elective surgeries, outpatient consultations have been drastically reduced. Parallel to these developments, an increase in telemedical consultations has reflected efforts to provide sufficient patient care. This study aims to evaluate the feasibility of a clinical examination of the hip joint and pelvis by way of a telemedical consultation.

Materials and Methods Twenty-nine patients of a German university clinic were recruited and assessed in both telemedical and conventional examinations. Agreement between the two examinations was then assessed, and connections between the observed agreement and patient-specific factors such as age, BMI and ASA classification were investigated.

Results The inspections agreed closely with a mean Cohen's kappa of $0.76 \pm 0.37$. Palpation showed adequate agreement with a mean Cohen's kappa of $0.38 \pm 0.19$. Function showed good agreement with a mean Cohen's kappa of $0.61 \pm 0.26$ and range of motion showed adequate agreement with a mean Cohen's kappa of $0.36 \pm 0.19$. A significant positive correlation was observed between the number of deviations in the different examinations and age $(p=0.05)$, and a significant positive correlation was shown between the number of non-feasible examinations and age $(p<0.01)$, BMI $(p<0.01)$ and ASA classification score $(p<0.01)$.

Discussion Inspection and function can be reliably evaluated, whereas the significance of palpation, provocation and measurement of range of motion is limited. The small sample size puts limitations on the significance of a statistically relevant correlation between patient-specific factors such as age, BMI and ASA classification score and valid and successful implementation of a telemedical examination. The authors recommend targeted patient selection. If, however, patients are being evaluated who are very old (>75 years), obese (BMI $>30$ ) or with multiple comorbidities (ASA 3 and above), caution is advised. Large, prospective studies are needed in the future to fully validate telemedical consultations in the fields of orthopaedics and trauma surgery.

Conclusion A telemedical examination of the hip joint and pelvis can be performed with certain limitations. Patient-specific factors such as age, BMI, and extent of comorbidities ap-

* equally contributing first authors

** equally contributing last authors 
pear to have a relevant impact on validity and execution of the examination. Patients with multiple comorbidities (ASA 3 and above), advanced age (>75 years) or obesity (BMI > 30) should, whenever possible, be examined in a conventional outpatient setting.

\section{ZUSAMMENFASSUNG}

Einleitung Aufgrund der aktuellen COVID-19-Pandemie erfolgten Einschränkungen im Fach der Orthopädie und Unfallchirurgie durch das Gesundheitsamt. Neben der Verlegung von elektiven operativen Eingriffen erfolgte auch die drastische Reduktion der Sprechstunden. Hierdurch kam es zu einem deutlichen Anstieg von telemedizinisch durchgeführten Sprechstunden zur Gewährleistung der Patientenversorgung. Die Zielsetzung dieser Arbeit ist, die Umsetzbarkeit einer klinisch-orthopädischen Untersuchung der Hüfte und des Beckens durch telemedizinische Verfahren im Rahmen einer Videosprechstunde zu untersuchen.

Material und Methoden Im Rahmen der vorliegenden Auswertung wurden 29 stationäre Patienten eines deutschen Universitätsklinikums rekrutiert und im Rahmen einer Videosprechstunde und konventionell untersucht. Anschließend wurde die Übereinstimmung der erhobenen Befunde ausgewertet und Zusammenhänge mit patientenspezifischen Daten wie Alter, BMI und ASA-Klassifikation untersucht.

Ergebnisse Es zeigte sich eine gute Übereinstimmung der Inspektion mit einem durchschnittlichen Cohens Kappa von $0,76 \pm 0,37$, eine angemessene Übereinstimmung der Palpation mit einem durchschnittlichen Cohens Kappa von $0,38 \pm 0,19$, eine gute Übereinstimmung der Funktion mit einem durchschnittlichen Cohens Kappa von 0,61 $\pm 0,26$ und eine angemessene Übereinstimmung der Bewegungsausmaße mit einem Cohens Kappa von 0,36 $\pm 0,19$. Es zeigte sich ein signifikanter positiver Zusammenhang zwischen Anzahl der Abweichungen der verschiedenen Untersuchungen und Alter $(p=0,05)$ und ein positiver signifikanter Zusammenhang zwischen Anzahl der nicht durchführbaren Untersuchungen und Alter $(p<0,01)$, BMI $(p<0,01)$ und ASA-Klassifikationswert $(p<0,01)$.

Diskussion Vor allem die Inspektion und Funktion sind gut untersuchbare Parameter während Palpation, Provokation und die Erfassung der Bewegungsausmaße eine limitierte Aussagekraft zeigen. Bei begrenzter Anzahl der Probanden ist die Aussagekraft eines statistisch relevanten Zusammenhangs zwischen patientenspezifischen Faktoren wie Alter, BMI und ASA-Klassifikationswert und der validen und erfolgreichen Durchführung einer telemedizinischen Untersuchung limitiert. Die Autoren sprechen sich für eine gezielte Patientenselektion aus. Sollten dennoch sehr alte (> 75 Jahren), adipöse (BMI > 30) oder stark vorerkrankte Patienten (ab ASA 3) untersucht werden, ist Vorsicht geboten. Es bedarf in der Zukunft weiterer großangelegter, prospektiver Studien, um eine ausreichende Validierung einer telemedizinischen Untersuchung in der Orthopädie und Unfallchirurgie zu erreichen.

Schlussfolgerung Die telemedizinische Untersuchung von Hüftgelenk und Becken ist mit Einschränkungen möglich. Patientenspezifische Faktoren wie Alter, BMI und Grad der Vorerkrankungen scheinen einen relevanten Einfluss auf die Validität und die Durchführung zu haben. Patienten, die stark vorerkrankt (ab ASA 3) sind, ein hohes Lebensalter haben (> 75 Jahre) und/oder adipös sind (BMI > 30), sollten, wenn möglich, in eine herkömmliche Sprechstunde einbestellt werden.

\section{Introduction}

In December of 2019, a previously unknown pathogen was identified in the city of Wuhan, Hubei Province, China, that causes a severe viral pneumonia. This novel disease pathogen, designated Severe Acute Respiratory Syndrome Coronavirus-2 (SARS-CoV-2), has since spread globally at a rate never before seen [1,2].

On 11 March 2020, this disease was declared a pandemic by the World Health Organization (WHO) [3,4]. To keep the national healthcare system from being overwhelmed as in Italy and Spain, the German government enacted multiple infection prevention measures in March. These measures included both postponement of elective surgeries and a drastic reduction in numbers of faceto-face patient consultations [5].

A rapid response is now necessary to ensure further comprehensive care of orthopaedic and trauma surgery patients. Telemedical consultations, also known as video appointments or video consultations, are one way of maintaining direct patient contact. Telemedical approaches have since seen greatly increased use in both Germany and the U.S. [6].

Use of telemedical consultations in orthopaedic and trauma surgery cases has been fairly limited in Germany to date due to the inherent restrictions of palpation and dynamic testing. As a result, experiential data and literature-based validation are limited. To our knowledge, no detailed investigations have been published to date with sufficient assessments of the feasibility of clinical hip joint and pelvic examination using this approach. Since urgent action is now required of orthopaedic and trauma surgery clinicians, validation and structuring of clinical telemedical examinations have become an inescapable necessity.

The COVID-19 pandemic is not the first "natural catastrophe" that has led to increased use of telemedical methods. Increased use of these methods was also observed in the aftermath of Hurricane Maria in Puerto Rico in 2017 [7].

Until the COVID-19 pandemic struck, the development of telemedical methods focused mainly on rural areas with limited medical resources [8]. Another area that saw a significant expansion of use of telemedicine was medical care of military troops in hard-toreach zones and at the front lines of conflicts [9].

The metaphoric front line is now closer to home due to the organizational restrictions presented by the COVID-19 pandemic. Even areas with ubiquitous medical care, such as large German cities, are now in a situation characterized by limits to patient care. Creativity in implementing and further expansion of the 
knowledge already gained in this field is now needed if we are to ensure patient care beyond an emergency framework.

Relevant experience has been gained in other medical fields. Maia et al. published an investigation of the paediatric telecardiological program, which has been used to examine a total of 32,685 patients over the past 20 years. They reported improved healthcare in Portugal and Africa based on a large volume of experiential data [10]. In a large-scale meta-analysis of telemedical diabetes mellitus therapy, the telemedical follow-up regimen even proved superior to the conventional approach [11].

In Norway, initial investigations in the field of orthopaedics showed that telemedical consultation within a defined patient cohort is safe and reliable and can operate cost-effectively in both social services and healthcare $[8,12]$.

If we are to be prepared to meet the challenges facing us, we must now investigate the use of telemedical methods in orthopaedics and trauma surgery.

This paper aims to investigate the feasibility of a clinical orthopaedic examination of the hip and pelvis using telemedical methods in video consultations. To this end, the reliability of the (virtual) clinical examination methods are assessed in comparison with a conventional physical presence examination by a physician. Further, the impact of individual patient factors are assessed for agreement between the examination methods.

\section{Material and Methods}

\section{Patient collective and data collection}

For this assessment, hospitalized patients in a German university clinic without prior known hip joint pathologies were recruited and, after informed consent was obtained, examined in a video consultation.

Exclusion criteria included significant cognitive impairments (e.g. dementia or mental retardation), recent hip joint and/or pelvic surgeries, prescribed partial loading/bedrest, refusal of consent, patient age under 18 years, language barriers and administration/intake of analgesics $>$ WHO II. 29 patients were included in the study following the selection process. Age, sex, height, weight, BMI and ASA classification were documented in addition to the examination results.

A total of 29 test subjects were evaluated for the present study, 14 female and 15 male. Average age was $61.9 \pm 17.1$ years. Average height was $1.72 \pm 0.10 \mathrm{~m}$, average body weight was $79.55 \pm 18.36 \mathrm{~kg}$. The resulting average BMI was $26.9 \pm 6.6$. The average ASA score was $2 \pm 0.7$.

The Ethics Committee of our institution assessed and approved the study prior to the start of data collection (Ethics Board Registration No. 163/2020).

\section{Organization of the examinations}

The test subject examinations were done in two segments, separated as to time and place. In the first step, a complete telemedical examination was performed by a single examiner. This procedure was based on the technical and organizational structure of the telemedical consultation as practised in our own clinic. The examiner used a standard clinical desktop computer (model Elite- desk, Hewlett-Packard, Wilmington, Delaware, USA) equipped with a webcam (model C270, Logitech, Newark, California, USA) and a headset (model H390, Logitech, Newark, California, USA). To simulate a mobile terminal, the patient was provided with a tablet computer (model iPad Pro, Apple, Cupertino, California, USA) with an integrated camera and microphone. Both the test subject and the examiner were able to follow the audio and video transmission, and to communicate, in real time on screen. The examiner could also pause the video transmission to draw in lines for angular and length measurements using a drawing tool. Audio transmission was not interrupted during this image evaluation procedure.

Following completion of the video examination, a conventional physical presence clinical examination by a physician was performed to validate the telemedical findings. This presence examination was also performed by the initial examiner to avoid any potential examiner-related interfering factors.

\section{Clinical examination}

A standardized examination form (see Annex) was used to structure the examination procedure. The examination form was developed within the framework of this study and has not yet been validated. It was used in both examination procedures to ensure uniformity the examination procedure.

The examination form intentionally omits patient health history since the aim of this study was to evaluate the feasibility of a clinical examination using telemedical methods.

The examination was structured based on 5 main categories (Inspection, Palpation, Function, Range of Motion and Provocation). The individual examination techniques involved were explained in detail to the patient before each procedure, in some cases with demonstration by the examiner. The patient was not supported by third persons (e.g. family members or medical staff) for the telemedical examination. To ensure the efficiency of the telemedical examination, if the explanation of a specific examination procedure was not understood the explanation was interrupted after 3 minutes if it proved non-feasible. The corresponding part of the examination was subsequently evaluated as nonassessable.

The examination form in the Annex lists the clinical examinations performed. The individual examination techniques were performed analogously to everyday clinical practice as far as possible. However, further adaptations were necessary for the following examination methods: For determination of the range of motion, active range of motion was measured for both examination procedures as per feasibility in the telemedical examination. The Drehmann sign procedure was performed actively by the patient, in a deviation from standard practice, in both examination procedures. Muscle strength evaluation was restricted to the categories: full range, against gravity, paralysis and non-assessable. Axial compression pain was demonstrated by having the patient exert compression on the affected leg while standing. The Thomas test was also actively performed by the patient, who was instructed to maintain contact between lower back and treatment table surface. 
- Table 1 Cohen's kappa values grouped according to the different examination methods.

\begin{tabular}{|c|c|}
\hline Examination & Cohen's к \\
\hline Inspection & $0.76 \pm 0.37$ \\
\hline - Swelling & 0.818 \\
\hline - Redness & 1.0 \\
\hline - Atrophy & 0.220 \\
\hline - Scar/wound anomalies & 1.0 \\
\hline Palpation & $0.38 \pm 0.19$ \\
\hline - Symphysis & 0.588 \\
\hline - Trochanter major & 0.223 \\
\hline - Groin & 0.209 \\
\hline - Gluteal & 0.482 \\
\hline Function & $0.61 \pm 0.26$ \\
\hline - Muscle strength hip flexion & 0.473 \\
\hline - Muscle strength hip extension & 1.0 \\
\hline - Muscle strength hip abduction & 0.482 \\
\hline - Muscle strength hip adduction & 0.482 \\
\hline - Gait & 1.0 \\
\hline - Feasibility of one-legged stand & 1.0 \\
\hline - Feasibility of knee bend & 1.0 \\
\hline Range of motion & $0.36 \pm 0.19$ \\
\hline - Extension/flexion & 0.380 \\
\hline - Outer rotation/inner rotation & 0.486 \\
\hline - Abduction/adduction & 0.265 \\
\hline Provocation tests & $0.33 \pm 0.13$ \\
\hline - Apley test & 0.181 \\
\hline - Drehmann sign & 0.386 \\
\hline - Trendelenburg sign & 0.281 \\
\hline - Axial compression pain & 0.475 \\
\hline . Thomas test & 0.370 \\
\hline - Posterior impingement test & 0.146 \\
\hline - Ventral impingement test & 0.147 \\
\hline - Foveal impingement test & 0.045 \\
\hline
\end{tabular}

\section{Statistical analysis}

Statistical analysis and graphics were done using SPSS Statistics Version 23 (IBM, Armonk, New York, USA). Significance was defined at $p<0.05$. Checking of the collected data for normal distribution was done using the Kolmogorov-Smirnov test. The Pearson coefficient of correlation was then calculated to check for a potential correlation of normally distributed metric data. The Spearman coefficient of correlation was used as a non-parametric correlation test. Nominally-scaled data were evaluated using the chi-squared test. In a cohort $\mathrm{n}<30$, a bootstrap sample was also derived to ensure correct determination of significance. To assess agreement of the two examination procedures beyond chance correlation, Cohen's kappa was determined. The Landis and Koch scale was used to evaluate agreement [13]. Therefore, kappa values above 0.80 were designated as excellent agreement, $0.61-0.80$ as good agreement, $0.41-0.60$ as moderate agreement, $0.21-0.40$ as adequate agreement and below 0.20 as poor agreement.

\section{Results}

The individual examinations were separately evaluated, then combined to obtain an average for the respective superordinate category (Inspection, Palpation, Function, Range of Motion and Provocation). The inspections agreed closely with a mean Cohen's kappa of $0.76 \pm 0.37$ (swelling $\mathrm{K}=0.818$; redness $\mathrm{K}=1.0$; atrophy $\mathrm{K}=0.220 ; \mathrm{scar} /$ wound anomalies $\mathrm{K}=1.0$ ). Palpation showed adequate agreement with a mean Cohen's kappa of $0.38 \pm 0.19$ (symphysis $\mathrm{K}=0.588$; trochanter major $\mathrm{K}=0.223$; groin $\mathrm{K}=0.209$; gluteal $\mathrm{K}=0.482$ ).

Function showed good agreement with a mean Cohen's kappa of $0.61 \pm 0.26$ and thus good agreement of the examinations (muscle strength hip flexion $\mathrm{K}=0.473$; muscle strength hip extension $\mathrm{K}=1.0$; muscle strength hip abduction $\mathrm{K}=0.482$; muscle strength hip adduction $\mathrm{K}=0.482$; gait $\mathrm{K}=1.0$; feasibility of onelegged stand $\mathrm{k}=1.0$; feasibility of knee bend $\mathrm{k}=1.0$ ). Evaluation of the clinical examination of range of motion showed adequate agreement with a mean Cohen's kappa of $0.36 \pm 0.19$ (extension/flexion $\mathrm{K}=0.380$; outer rotation/inner rotation $\mathrm{K}=0.486$; $\mathrm{ab}$ duction/adduction $\mathrm{k}=0.265$ ). Analysis of the various provocation tests also revealed merely adequate agreement of the different examination procedures with a Cohen's kappa of $0.33 \pm 0.13$ (Apley test $\mathrm{k}=0.181$; Drehmann sign $\mathrm{k}=0.386$; Patrick's test $\mathrm{K}=0.291$; Trendelenburg sign $\mathrm{K}=0.475$; axial compression pain $\mathrm{K}=0.1$; Thomas test $\mathrm{K}=0.370$; posterior impingement test $\mathrm{K}=0.146$; ventral impingement test $\mathrm{K}=0.147$; foveal impingement test $\mathrm{K}=0.045$ ). $>$ Fig. 1 shows an overview of the Cohen's kappa values grouped according to the examination categories. The individual Cohen's kappa values are also listed in $>$ Table 1.

The correlation analysis revealed a significant positive correlation between age and number of deviations among the different examinations $(r=0.588 p<0.01)$. Test subject sex showed neither a significant effect on the number of deviations among the different examinations $(p=0.55)$ nor on the number of examinations that proved telemedically non-assessable $(p=0.52)$. Both BMI $(r=0.389 p<0.05)$ and ASA $(r=0.396 p<0.05)$ correlate significantly with an increasing number of deviations between telemedical and conventional examinations. A significant positive correlation of telemedically non-assessable examination results was also observed with the ASA classification score $(r=0.509 p<0.01)$, BMI $(r=0.485 p<0.01)$ and age $(r=0.579 p<0.01)$. The correlations of BMl and age with the rate of non-assessable examination methods are illustrated by way of example in $\boldsymbol{\nabla}$ Fig. $\mathbf{2}$.

\section{Discussion}

This study evaluated the feasibility of telemedical examination of the hip joint and pelvis. Good agreement of results with a conventional clinical examination was observed for the categories Inspection and Function. The evaluation of Range of Motion revealed only moderate agreement. Palpation and Provocation showed only adequate correlations between the examination results. The correlation analysis with patient-specific factors showed 


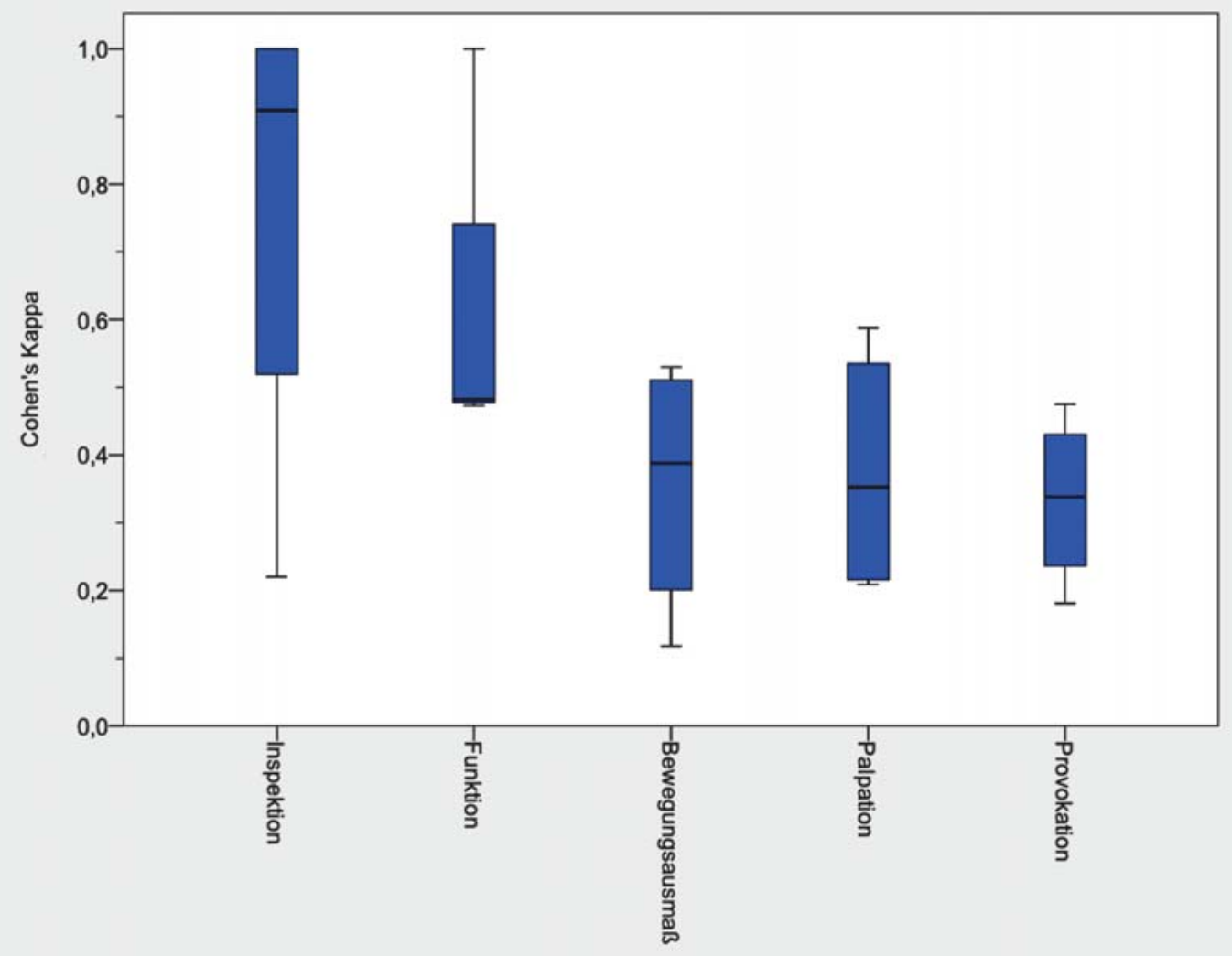

- Fig. 1 Agreement between modalities grouped according to examination categories.
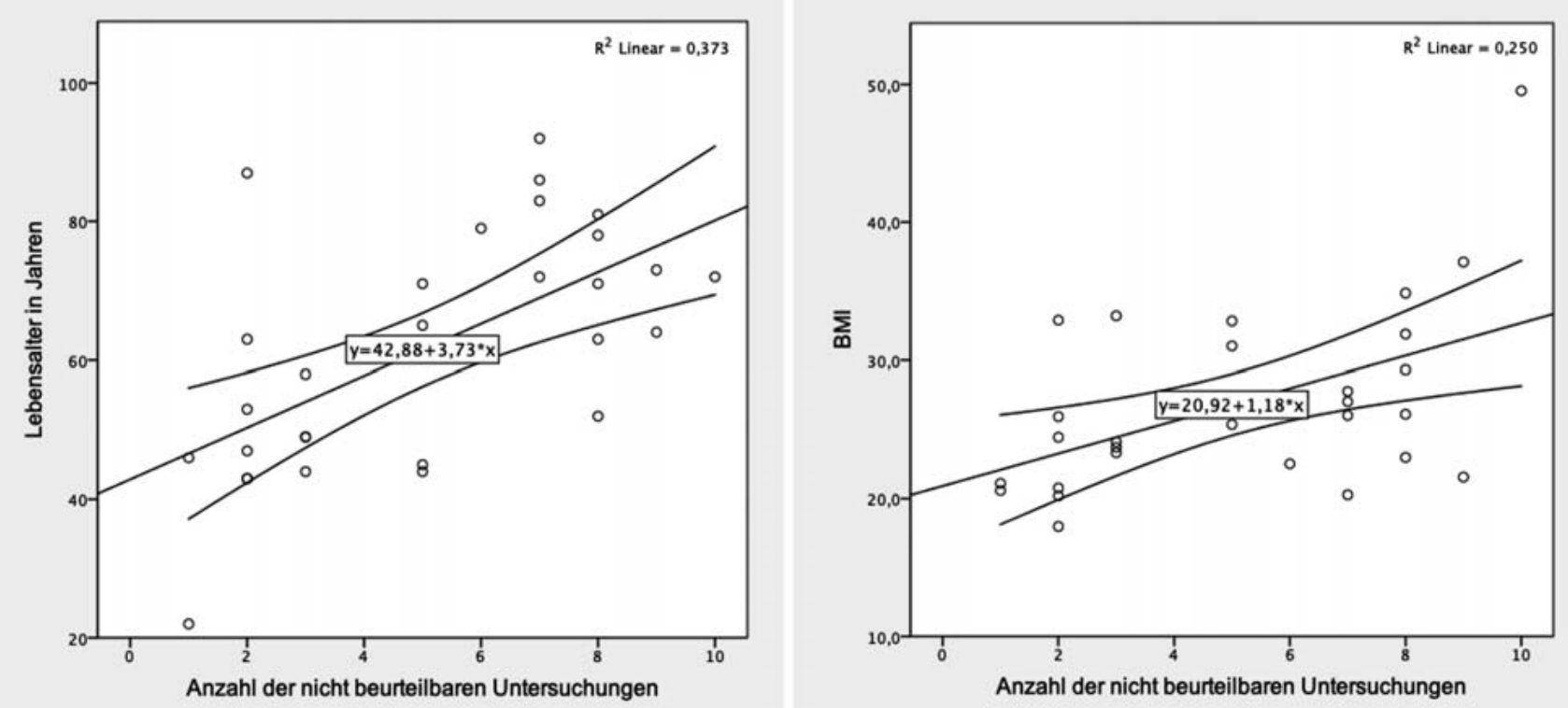

- Fig. 2 Scatter diagram of correlation between age in years and BMI with the number of non-feasible examinations. 
a significant positive correlation between age, BMI and ASA classification score and the rate of deviations between the two examinations as well as the number of non-assessable tests.

Inspection was shown in this study to be readily feasible in a telemedical consultation. Good agreement was seen between telemedical and conventional findings. This finding opens up possibilities for a number of diagnoses and follow-up examinations, e. g. wound monitoring. Caution is advised in evaluation of atrophies and in highly adipose patients. Evaluation of coarse pelvic and hip function based on telemedical examination is valid.

However, specification of pelvic and hip joint function, for example by exact determination of ranges of motion, showed only moderate agreement. This may have to do with the active character of the motions. Patients experiencing pain tend to avoid positions that elicit further pain. Further, even assuming proper execution by the patients, there are many influencing factors that can reduce measurement accuracy. Investigations already published in the literature differ, for instance claiming only moderate results for the wrist and good agreement for elbow evaluations $[14,15]$.

Provocation testing was determined to be not reliably assessable in our study design. Agreement with a conventional clinical examination were minimal at best. These results are supported by a physiotherapeutic meta-analysis by Mani et al. [16]. Here as well, it may be that the underlying mechanism is conscious or unconscious pain avoidance by the test subjects. To avoid influencing the examiner, this assessment intentionally omitted structured health history reports, whereas recording of a thorough health history is an absolute necessity in conventional clinical examination practice. A structured health history assumes a special significance in telemedical evaluation of the hip joint and pelvis. Particularly in view of the limited information value of specific function and provocation tests, detailed information provided by the patient can provide essential diagnostic information. It could be concluded that the limited information value of telemedical provocation test assessment could be improved by a specific health history. However, since the present study did not evaluate this connection, further studies would be required to reach a conclusive assessment.

Patient selection represents an essential aspect of setup and optimization of a telemedical consultation. As far as the authors are aware, no current studies have been published that cover this aspect adequately. Various recommendations have been published, but validation has not been established [17 - 19].

This assessment revealed a statistically relevant connection between patient-specific factors such as age, BMI and ASA classification score and the valid and successful performance of a telemedical examination. However, since the number of test subjects is small, a differentiated view of the value of the statistical evaluation and its interpretation is necessary. Even though the limited collective in this study cannot provide definitive conclusions regarding significance and causality, the results do highlight the importance of adequate patient selection. This study cannot provide definitive conclusions regarding inclusion and exclusion criteria, but results for patients with the following characteristics must be interpreted cautiously: The present assessment, supported by the subjective perception of the examiner, tends to the view that a telemedical examination has limited validity for older, adipose and multimorbid patients. In such cases, the examiner must be aware that the significance of the results of a telemedical examination may be limited and that an additional conventional face-toface consultation should be arranged if the doubts appear wellfounded.

In the end, patient and physician acceptance of a telemedical examination must be the goal. Here as well, pitfalls abound. In the literature, it appears that the patients who willingly undergo a telemedical consultation are those without major health problems, whereas patients with relevant symptoms tend to be sceptical of the new methods [20]. Generally speaking, patients appear to view the notion of telemedical consultation critically [21].

Telemedicine, not a novel invention, is increasingly important in the COVID-19 crisis. The suitability of telemedical consultations in specific fields of application has already been shown. In telemedical consultations in Denmark, improved fast-track capacities were demonstrated, resulting in earlier patient discharges without any relevant risk to patient satisfaction [22]. Good results were also achieved in a telemedical rehabilitation programme with patients with lower extremity injuries [23]. Time will tell whether these results can be extrapolated to larger patient collectives and broader contexts. One possible task of a telemedical consultation service could be targeted triage with the aim of determining whether a conventional consultation is necessary and how urgent such an appointment is. Telemedical preselection and assignment to conventional consultation appointments is also conceivable. These applications would open a channel of communication that would demand relatively little patient effort.

The relatively small test subject collective is one of the main limitations of this study. In future, additional large-scale prospective studies will be required to achieve adequate validation of telemedical examinations in orthopaedics and trauma surgery. Given the many different hip pathologies one sees in a conventional consultation practice, large case numbers with sufficient test subjects for each clinical picture will be necessary if the assessment of diagnostic sensitivity and specificity for defined pathologies is to be of sufficient quality. The present study cannot draw conclusions of this scope due to the limited number of test subjects. It can therefore serve as a pilot study considering the possibility, in principle, of examining the hip joint telemedically. We therefore decided to limit the recruited patient collective to patients with no hip joint pathologies. More extensive follow-up studies can now be designed on this basis. The current state of scientific knowledge is still insufficient to support a definitive assessment of the sufficiency of telemedical examination. Statistical evaluations determine only correlations that do not necessarily reflect causality. Here as well, future studies with much larger collectives will provide important and interesting results. Further, the clinical examinations in this study were performed without prior training of the test subjects. Additional studies must determine whether a structured patient information sheet would improve agreement. It must also be noted that little experiential data has been collected on clinical telemedical examination. In time and with increasing establishment of the method, data from experience, as well as increased structuring and optimization of the examination procedure, could also impact future results. This study also did 
not collect information on previous patient experience with clinical hip joint and pelvis examinations. The patients in this case were hospitalized orthopaedic patients classified as having healthy hip joints when the data were collected. Nonetheless, the possibility of previous experience and clinical examination of the hip joint and pelvis in an inpatient context cannot be excluded and could result in bias accordingly.

The patients in our study were provided with a high-quality terminal device to prevent any impact of technical equipment quality. Everyday clinical practice will however of course involve contacts with patients whose equipment is older or whose internet connection is poor. As far as the authors are aware, no definitions have been arrived at regarding minimum quality standards in this respect, although this could potentially have a considerable negative impact on an examination.

\section{Conclusion}

It was shown in this study that a telemedical examination is possible within limits. Patient-specific factors such as age, BMI and levels of prior morbidities would appear to have a relevant impact on validity and execution.

As the matter currently stands, targeted patient selection is a must, whereby patients should meet the technical, physical and cognitive preconditions required to ensure a reliable examination. Patients with severe prior morbidities, advanced age and/or adiposity may predispose the telemedical examination to limited significance of the results obtained. We recommend considering the findings in this cohort with caution, with arrangement of an additional conventional examination appointment as indicated.

It is the assumption of the authors that the near future will see the existing results significantly augmented by experience, telemedically adapted examination techniques and technical innovations such as augmented reality and artificial intelligence. Whether telemedical assessment of patients currently considered poorly suited for this approach will then be acceptably valid remains to be seen. Possible applications of telemedicine within the framework of an orthopaedic and trauma surgery hip and pelvic consultation include triaging and assignment of patients to conventional appointments and performance of clinical followup monitoring, e.g. of wounds and swellings. This study establishes a starting point for scientific work on the theme of telemedical hip and pelvis examinations. It can serve as a reference for future work and will hopefully provide motivation for further investigations of this interesting and relevant thematic complex. Telemedical applications are being developed apace, with the current COVID-19 pandemic providing the impetus to anchor them in standard clinical practice.

\section{Conflict of Interest}

The authors declare that they have no conflict of interest.

\section{References}

[1] Zhu N, Zhang D, Wang W et al. A Novel Coronavirus from Patients with Pneumonia in China, 2019. N Engl J Med 2020; 382: 727-733. doi:10.1056/NEJMoa2001017

[2] Lu R, Zhao X, Li J et al. Genomic characterisation and epidemiology of 2019 novel coronavirus: implications for virus origins and receptor binding. Lancet 2020; 395: 565-574. doi:10.1016/S0140-6736(20)30251-8

[3] Cucinotta D, Vanelli M. WHO Declares COVID-19 a Pandemic. Acta Biomed 2020; 91: 157-160. doi:10.23750/abm.v91i1.9397

[4] Tian H, Liu Y, Li Y et al. An investigation of transmission control measures during the first 50 days of the COVID-19 epidemic in China. Science 2020; 368: 638-642. doi:10.1126/science.abb6105

[5] Bundesministerium für Gesundheit. Coronavirus SARS-CoV-2 (11.03.2020). Im Internet (Stand: 10.09.2020): www.bundesgesundheitsministerium.de/coronavirus/chronik-coronavirus.html

[6] U.S. Centers for Medicare \& Medicaid Services. Telehealth services (01.02.2020). Im Internet (Stand: 10.09.2020): www.cms.gov/Outreachand-Education/Medicare-Learning-Network-MLN/MLNProducts/ Downloads/TelehealthSrvcsfctsht.pdf

[7] Lurie N, Carr BG. The Role of Telehealth in the Medical Response to Disasters. JAMA Intern Med 2018; 178: 745-746. doi:10.1001/jamainternmed.2018.1314

[8] Buvik A, Bugge E, Knutsen G et al. Quality of care for remote orthopaedic consultations using telemedicine: a randomised controlled trial. BMC Health Serv Res 2016; 16: 483. doi:10.1186/s12913-016-1717-7

[9] The White House. President Trump and Secretary Shulkin Announce Veteran Telehealth Initiatives (03.08.2017). Im Internet (Stand: 10.09.2020): https://www.whitehouse.gov/articles/president-trumpsecretary-shulkin-announce-veteran-telehealth-initiatives/

[10] Maia MR, Castela E, Pires A et al. How to develop a sustainable telemedicine service? A Pediatric Telecardiology Service 20 years on - an exploratory study. BMC Health Serv Res 2019; 19: 681. doi:10.1186/s12913019-4511-5

[11] Tchero H, Kangambega P, Briatte $C$ et al. Clinical Effectiveness of Telemedicine in Diabetes Mellitus: A Meta-Analysis of 42 Randomized Controlled Trials. Telemed J E Health 2019; 25: 569-583. doi:10.1089/ tmj.2018.0128

[12] Buvik A, Bergmo TS, Bugge E et al. Cost-Effectiveness of Telemedicine in Remote Orthopedic Consultations: Randomized Controlled Trial. J Med Internet Res 2019; 21: e11330. doi:10.2196/11330

[13] Landis JR, Koch GG. The measurement of observer agreement for categorical data. Biometrics 1977; 33: 159-174

[14] Scott KL, Skotak CM, Renfree KJ. Remote Assessment of Wrist Range of Motion: Inter- and Intra-Observer Agreement of Provider Estimation and Direct Measurement with Photographs and Tracings. J Hand Surg Am 2019; 44: 954-965. doi:10.1016/j.jhsa.2019.05.017

[15] Dent PA jr., Wilke B, Terkonda S et al. Validation of Teleconference-based Goniometry for Measuring Elbow Joint Range of Motion. Cureus 2020; 12: e6925. doi:10.7759/cureus.6925

[16] Mani S, Sharma S, Omar B et al. Validity and reliability of Internet-based physiotherapy assessment for musculoskeletal disorders: a systematic review. J Telemed Telecare 2016; 23: 379-391. doi:10.1177| $1357633 \times 16642369$

[17] Loeb AE, Rao SS, Ficke JR et al. Departmental Experience and Lessons Learned With Accelerated Introduction of Telemedicine During the COVID-19 Crisis. J Am Acad Orthop Surg 2020; 28: e469-e476. doi:10.5435/JAAOS-D-20-00380

[18] Rao SS, Loeb AE, Amin RM et al. Establishing Telemedicine in an Academic Total Joint Arthroplasty Practice: Needs and Opportunities Highlighted by the COVID-19 Pandemic. Arthroplast Today 2020; 6: 617622. doi:10.1016/j.artd.2020.04.014 
[19] Tanaka M], Oh LS, Martin SD et al. Telemedicine in the Era of COVID-19: The Virtual Orthopaedic Examination. J Bone Joint Surg Am 2020; 102: e57. doi:10.2106/JBJS.20.00609

[20] Parkes RJ, Palmer J, Wingham J et al. Is virtual clinic follow-up of hip and knee joint replacement acceptable to patients and clinicians? A sequential mixed methods evaluation. BMJ Open Qual 2019; 8: e000502. doi:10.1136/bmjoq-2018-000502
[21] Holderried M, Schlipf M, Höper A et al. Chancen und Risiken der Telemedizin in der Orthopädie und Unfallchirurgie. Z Orthop Unfall 2017; 156: 68-77. doi:10.1055/s-0043-116941

[22] Vesterby MS, Pedersen PU, Laursen M et al. Telemedicine support shortens length of stay after fast-track hip replacement. Acta Orthop 2016; 88: 1-7. doi:10.1080/17453674.2016

[23] Tsvyakh Al, Hospodarskyy AJ. Telerehabilitation of Patients with Injuries of the Lower Extremities. Telemed J E Health 2017; 23: 1011-1015. doi:10.1089/tmj.2016.0267 